\title{
A hora da aula e o tempo da história nos estudos literários: uma entrevista com Eduardo Sterzi
}

\section{Class hour and history time in literary studies: an interview with Eduardo Sterzi}

\author{
Eduardo Jorge de Oliveira* \\ Universidade de Zurique \\ eduardo.jorge@rom.uzh.ch
}

Cinquenta minutos. Muitas vezes esse tempo cronometrado é, por um lado, extremamente objetivo sob a forma de créditos escolares a ser contabilizado no final de um curso ou matéria sob a forma de diploma que, por sua vez, ficará estampado nos históricos escolares. Por outro lado, existe um tempo incalculável, uma matéria que escapa do objetivo de uma única aula ou de um curso e uma formação dedicada à língua e à literatura como é o caso das Letras. Muitos professores lidam com dilemas das obras que figuram nas exigências curriculares e que diversos estudantes irão ler e reler até estarem seguros da visão de um autor, de um período ou das relações que uma obra pode ter com outras, suas intertextualidades e transtextualidades com as quais um texto literário se relaciona a partir de experiências de leitura.

Tanto nas escolas quanto nas universidades um professor de literatura pode transportar os estudantes para as mais distintas épocas e espaços, de Ítaca a Itabira, nos quais a literatura tem esse poder de fazer sonhar acordado enquanto se lê ou se escuta um professor ou professora em sala de aula. Cada um dos estudantes experimenta diferentemente as sensações da leitura com Homero, Drummond ou Leminski, por exemplo, ou Penélope, Safo ou Sherazade ao descobrir palavras ou lidar com a carga emotiva de peças literárias das contemporâneas até as mais antigas do que a própria ideia de literatura. Ser Homero é também ser leitor de textos e de situações. A literatura também nos ajuda a nos situar diante de problemas e desafios de cada momento, sem por isso, render-se tão somente à uma função documental do presente ou de uma determinada época, de modo que se pode fazer eco à frase de Ana Cristina César, "literatura não é documento". Eco que possui uma dimensão crítica sobre os valores que circulavam em torno da literatura e das ferramentas

\footnotetext{
*Professor Assistente de Brasilianística no Seminário de Romanística da Universität Zürich.
} 
pedagógicas que, atreladas a autores e textos, se passam por nacional sobretudo do ponto de vista moral.

Dado que os conceitos e as teorias se movem tanto por exposições detalhadas quanto por discussões calorosas, até mesmo o cânone participa desta instabilidade enquanto os próprios textos literários nos mais diversos gêneros se valem de margens de manobra para ocupar espaços e ampliar a própria política de leitura. O que mostra que uma aula de literatura possui uma vocação política no sentido mais amplo do termo lidar com as contradições, ambivalências e decisões no âmbito da leitura. Direito à literatura, reivindicaria Antonio Candido (2011, p. 179) para afirmar que "a produção literária tira as palavras do nada e as dispõe como todo articulado." E esse todo possui uma grande mobilidade em sala de aula que cabe recorrer às palavras de João Adolfo Hansen (2019, p.105) para afirmar que:

A aula não é a mera exposição de um assunto por meio de uma técnica mais ou menos precisa, mas uma experiência intersubjetiva singular que é extremamente contingente, quero dizer, experiência dinâmica sempre caracterizada por um equilíbrio muito precário, sujeito a imprevistos, tendo, por isso mesmo, de incorporar e transformar o que ocorre no momento em que ocorre para ser eficaz.

A entrevista com Eduardo Sterzi, ${ }^{1}$ Professor de Teoria Literária na Universidade de Campinas - UNICAMP, expõe alguns aspectos da aula de literatura e do tempo da história literária. Essa conversa aspectos que conectam a literatura, seus saberes diretos e indiretos, relações de força entre história e historiografia literária além da aula [de literatura] como um acontecimento único, uma força além do conteúdo ou das técnicas pedagógicas de ensino. Em outras palavras, conforme afirmou Eduardo Sterzi na entrevista que segue: "Ora, a literatura, quando funciona como literatura, isto é, como singularidade, não ilustra - ela, antes, perturba a transmissão de qualquer conhecimento, inclusive o conhecimento da própria literatura". Essa matéria em movimento feita de palavras, baseada no como dizer, escrever e contar por vezes faz

\footnotetext{
1 Eduardo Sterzi nasceu em Porto Alegre, em 1973, e vive em São Paulo desde 2001. Seu primeiro livro, Prosa (2001), conquistou o Prêmio Açoriano de Literatura na categoria Autor-Revelação em Poesia. É autor também de dois volumes de estudos literários : Por que ler Dante e A prova dos nove : alguma poesia moderna e a tarefa da alegria (ambos de 2008), além de ter organizado Do céu do futuro: cinco ensaios sobre Augusto de Campos (2006). É doutor em Teoria e História Literária pela Universidade Estadual de Campinas - Unicamp e realizou pesquisas de pós-doutorado na Universidade de São Paulo e na Università degli Studi di Roma La Sapienza. É professor de Teoria Literária do Instituto de Estudos da Linguagem da Unicamp.
} 
coincidir a hora da aula e o tempo da história. Tempo plural com seus efeitos atrasados ou com antecipações, pois nem sempre o presente é capaz de contê-lo. Há tempos específicos que fazem da aula um acontecimento único.

1 Caro Eduardo Sterzi, gostaria de iniciar essa conversa com o termo "aula de literatura". $O$ que surge na sua memória de estudante e na sua experiência de professor? se é possível separar claramente esses papeis. Assim, para além da distinção desses papeis no desdobramento da primeira questão, existem aulas das quais você ainda se lembra e que lhe marcaram como eventos únicos?

Curiosamente, a recordação mais nítida ou, pelo menos, persistente que tenho de uma aula de literatura não é de uma aula propriamente de literatura, mas, sim, de uma aula de física. Explico-me: tive, no Colégio Anchieta, em Porto Alegre, um grande professor de Física, Carlos Alberto Gianotti, que era dotado não só de um perfeito conhecimento da matéria, mas também tinha o talento dramático adequado para dar aulas. Lembro que, na primeira aula do curso, ele perguntou aos alunos se conhecíamos o poema "O artista inconfessável", de João Cabral de Melo Neto. Éramos alunos do então "primeiro grau", nenhum de nós conhecia o poema de Cabral - lembro até que alguns colegas, típicos sabichões, isto é, ignorantes completos, formularam a hipótese de que o poema não existiria... Volta e meia, ao longo do ano, ele retomava a pergunta, de forma teatral, pressupondo, imagino, que responderíamos negativamente, adivinhando a falta de curiosidade da maioria. Porém, alguns de nós, no entretempo, leram o poema na biblioteca do colégio - mas mesmo estes, entre os quais eu, preferiam dizer que não conheciam o poema para não interromper o jogo teatral que se estabelecera e que atravessaria o ano. Até que, na última aula, o professor Gianotti nos disse o poema com tal inteligência do seu conteúdo, e com graça tão compatível com a forma, que o acontecimento fez-se literalmente inesquecível - tanto que o estou relembrando aqui. Não me lembro se ele chegou a comentar o poema, e a sua relação com o curso que concluía, mas o que importa é que, de uma forma ou de outra, a própria leitura, feita do modo como ele a fez, como ápice de uma longa expectativa, a um só tempo teatral mas contida (ele disse o poema, não o "recitou"), deixou tudo às claras, pelo menos para os bons entendedores, e ainda que só hoje talvez eu consiga colocar aquela percepção em palavras mais ou menos justas: posso dizer que aprendi naquele momento que um 
poema se faz não só de palavras, mas de tempo (do manejo do tempo, do jogo entre expectativas e preenchimentos); que a literatura, por mais encerrada em si mesma (e o estrito esquema de rimas do poema, em que as palavras rimam consigo mesmas, parece levar ao extremo tal encerramento), sempre ilumina uma porção do mundo, que ela nos ajuda a ver, ou mesmo dá a ver, ainda que sob a forma de figuras, com diferença e estranhamento; que uma aula é um evento único, mas, ao mesmo tempo, parte de uma sequência - o curso - , e que, portanto, o bom professor deve se preparar para se deslocar continuamente entre o instante e a duração mais longa, atento à série narrativa que está construindo (trata-se, sempre, de contar uma história), sem descurar, porém, da intensidade teatral de cada movimento; que a poesia, como o ensino, pode ser uma ética, a ética de um fazer que não se faz na expectativa de nenhum reconhecimento imediato ou qualquer outra forma de recompensa, mas, sim, pelo compromisso com o próprio fazer, pelo nexo com a poiesis que nos coube:

Fazer o que seja é inútil.

Não fazer nada é inútil.

Mas entre fazer e não fazer

mais vale o inútil do fazer.

Mas não, fazer para esquecer

que é inútil: nunca o esquecer.

Mas fazer o inútil sabendo

que ele é inútil e que seu sentido

não será sequer pressentido,

fazer: porque ele é mais difícil

do que não fazer, e difícil-

mente se poderá dizer

com mais desdém, ou então dizer

mais direto ao leitor Ninguém

que o feito o foi para ninguém.

Esse mesmo tipo de sabedoria reconheci, depois, em cada um dos grandes professores com que me deparei, seja no curso de Jornalismo, em que me graduei, seja depois no mestrado e no doutorado, ambos em Teoria Literária. No Jornalismo, são inesquecíveis as aulas do professor Wladimir Ungaretti, aulas inclassificáveis e irrepetíveis, cada uma delas dividida em capítulos, com frequentes alusões a livros de literatura e de filosofia (mas também de outros campos) que deveríamos ler, mas nunca de forma obrigatória, tudo de mistura com recordações de causos e personagens exemplares, comentários sobre as notícias da semana e sua cobertura 
pela imprensa etc. Das aulas na Teoria da Literatura da PUCRS, onde fiz mestrado, recordo-me especialmente de algumas observações da professora Maria da Glória Bordini, por exemplo quando chamou a atenção para o fato de que, se alguém quisesse interpretar Mário Quintana de forma semelhante a como Walter Benjamin fez com Baudelaire, teria de dar atenção às leituras heterodoxas que agradavam ao poeta, como aquela da revista Planeta, dedicada a temas como OVNIs e extraterrestres. Uma análise materialista, dizia ela, tem que atentar para as coisas concretas, por mais imprevistas que sejam. Do doutorado em Teoria e História Literária da UNICAMP, tenho ótimas lembranças das aulas de Hermenêutica da professora Jeanne-Marie Gagnebin, assim como do curso de História Literária que tivemos com os professores convidados Ettore Finazzi-Agrò e Roberto Vecchi. São aulas que, como as outras que aqui rememorei, continuam a alimentar minha prática de leitor crítico de literatura, mas também de professor. Quanto às minhas próprias aulas como professor, é difícil falar. Os alunos saberão dizer melhor do que eu se há nelas algo de memorável. Posso dizer, porém, que o maior prêmio que recebo como professor é quando algum aluno vem me dizer que uma aula ou curso que dei mudou a sua maneira de pensar - ainda mais quando se trata de algum aluno de Letras (isso acontece menos nos Estudos Literários, por razões óbvias) que diz que até então se interessava pouco por literatura e que, graças ao que eu disse ou às indicações de textos que fiz, isso mudou.

\section{Ainda em um plano mais amplo, desta vez sobre o ensino, como você escreveria um verbete para "aula"?}

Mário Pedrosa falou da arte como "exercício experimental da liberdade". Talvez dê para pensar em algo semelhante com relação à aula. Eu diria que é um exercício experimental do saber como liberdade. Não existe aula, a rigor, pelo menos como eu as concebo, sem as ideias de experiência e liberdade. Já dei cursos sobre matérias espinhosas, por exemplo, um curso de teoria queer voltado para as figurações trans na literatura e nas outras artes. Consciente de que as redes sociais criaram um ambiente intelectual (ou anti-intelectual) muito crispado, em que cada um parece se sentir muito confortável no papel de polícia dos comportamentos e discursos alheios, tanto à direita quanto à esquerda, fiz questão de começar o curso alertando aos alunos que, ao longo daquelas aulas, não admitiria que ficássemos vigiando a forma de falar 
uns dos outros, à procura de eventuais deslizes (uma flexão de gênero mal empregada, um artigo o em vez de a antes da palavra travesti etc.), por mais que soubéssemos que havia, hoje, modos mais apropriados e modos menos apropriados de falar e escrever algumas palavras; e minha advertência não era nenhuma defesa da incorreção política (acho que ninguém a teria interpretado assim), mas, sim, uma aposta na convicção de que o mais importante, até para que compreendêssemos melhor a relação entre linguagem, literatura e gêneros, era que todos pudéssemos pensar e falar livremente sobre as questões trazidas à baila pelas leituras. $E$ quando digo, seguindo Pedrosa, que uma aula é um exercício experimental, o que quero frisar é que não acredito que o que aconteça numa aula seja uma transmissão de conhecimentos - isto, aliás, é feito de modo muito mais eficaz por qualquer texto. A singularidade da aula está em transformar os textos lidos - tanto os literários quanto os críticos, teóricos, filosóficos, históricos etc. - novamente em experiências de pensamento, repensando o que já está pensado, ousando ir além, criando novos conceitos, lançando novas hipóteses. E falar em experiência e liberdade é também falar em contingência. O mais espantoso de uma aula é que, por mais que tenhamos um roteiro previsto, o que realmente conta nela é o que surge ao longo do seu próprio acontecer, aquilo que foge ao roteiro ou mesmo que explode o roteiro. É nesse momento, aliás, que, a meu ver, a aula realmente se faz.

3 A questão sobre a qual poderíamos insistir é justamente esta: a do contraste entre o plano da aula, experiência de ensino e espaço de improviso. Como você muito bem situou a partir de Mário Pedrosa, exercício experimental do saber como liberdade e, talvez, para afirmar mais próximo de Walter Benjamin, qual ou quais seriam as margens de manobra de um professor universitário de literatura entre esses três pontos, sobretudo para aqueles em que nada pode escapar do roteiro.

Acho que um professor que não pode escapar do roteiro está, com o perdão pela sinceridade bruta, na profissão errada. O que mais espero, numa aula, para que ela se constitua realmente como aula (diferentemente de uma palestra ou de qualquer outra forma de preleção sem expectativa de interferência, diálogo e ruído), é que venha, na hora certa (porque tudo aí, por ser experimental, é uma questão de kairós, de tempo propício), aquela intervenção por parte de um aluno que me fará desviar do 
roteiro. A manutenção férrea do roteiro dá, ao professor e talvez também aos alunos, uma ilusão de segurança e de adesão ao significado que, porém, no caso da literatura, me parece não só contraproducente, mas realmente antagônico com relação aos aspectos próprios da leitura de textos literários, que deve ser a base deste ensino. $\mathrm{O}$ que quero dizer com isso? Que o significado de um texto literário, salvo engano, nunca é algo dado de uma vez por todas e que pudesse, portanto, se achar sintetizado como tal no roteiro da aula. É, sim, o produto sempre em produção de um exercício virtualmente infinito de leitura e comentário - menos significado do que significação. Sendo assim, tenho a impressão de que é justamente no momento da fuga do roteiro que a leitura faz-se de fato literária, isto é, condizente com os seus objetos.

\section{Literatura e historiografia. Como aproximar, distinguir e confrontar com a} análise focalizada em textos precisos e situá-los em um panorama histórico que não obedeça a critérios evolucionistas, teleológicos e que, ao mesmo tempo, sejam claros e precisos para a apresentação do texto e do contexto?

Para mim, a questão da história da literatura é fundamental, tão fundamental quanto a questão da própria literatura, contanto que se tenha a noção de que o que chamamos de história da literatura não pode ser mais uma reiteração ou mesmo apenas uma adaptação dos antigos esquemas periodológicos, que tudo parecem explicar - o que é o Romantismo, o que é o Modernismo etc. - contanto que se perca de vista a singularidade das obras e também, em outro plano, as polarizações e contradições inerentes a cada período, achatando tudo numa série de características que, porém, não se verificam, se a análise for mais ou menos rigorosa, em nenhuma obra. Pelo contrário, se a história da literatura me parece fundamental, é porque a própria literatura é feita, em grande parte, de manejo figurativo do tempo e da sociedade (e portanto, da história), e, assim sendo, recontar a história da literatura não é apenas encaixar cada obra, autor ou escola numa determinada gaveta no armário do tempo, mas, sim, perceber a maneira como cada obra, cada autor, cada escola ou movimento reformula a própria noção de história e a própria série histórica, produzindo, assim, para si uma hipótese de inserção na sequência que, se a obra for poeticamente potente, ela mesma está fabricando nos momentos sucessivos e integrados, porém radicalmente contingentes, de sua escrita, publicação e leitura. $O$ grande desafio, do ponto de vista didático, talvez seja descobrir como transpor para a 
forma-aula - que exige alguma síntese comunicativa - essa reconstrução do movimento das próprias obras com relação à história da literatura, sem trair a complexidade dessa operação em nome de uma clareza da exposição que, por vezes, pode ser não realmente clareza, mas somente o conforto de recorrer mais uma vez aos esquemas históricos já consagrados. Como disse há pouco, interessa-me o aspecto experimental da aula - e acho razoável esticar sempre um pouco a corda da interpretação com relação ao previsível e sobretudo com relação ao já estabelecido.

\section{$5 \mathrm{E}$ quais seriam no seu ponto de vista os professores que melhor conciliaram ou teriam conciliado história da literatura, crítica literária e o tempo da aula?}

É uma pergunta difícil de responder, porque exigiria que eu conhecesse extensamente a prática em sala de aula de muitos dos nossos colegas. Temos aí uma impossibilidade física: desconheço em detalhe a prática em sala de aula inclusive da maioria dos meus colegas de departamento, quanto mais de professores de outras universidades. Conhecemos, porém, com alguma abrangência, os textos escritos por críticos literários e historiadores da literatura que são também professores e que, muitas vezes, deixam mais ou menos evidente o seu caráter de rastro da experiência didática. No Brasil, vê-se isso nos textos de Antonio Candido e Haroldo de Campos, de quem só assisti palestras, não aulas propriamente ditas, mas sobre cujas aulas temos tantos relatos vívidos de ex-alunos. Aliás, talvez fosse interessante estudar um gênero à parte na literatura sobre educação, que é o das recordações de alunos. Não sei se alguém já se interessou por fazer isso de forma mais sistemática - havia um projeto do Osvaldo Manuel Silvestre em torno das aulas e a ideia de aula de Antonio Candido, não sei se avançou; mas talvez valesse a pena fazer isso de forma comparativa, colocando lado a lado Candido e Haroldo, ou ainda Roberto Schwarz e Luiz Costa Lima. Não vidas paralelas, mas aulas paralelas. Há toda uma mitologia da aula que assim se produz - e que, a meu ver, quando não imobiliza os novos professores, pode ser inspiradora. A propósito, gosto sempre de recordar uma dedicatória muito bonita do Segismundo Spina, no Na madrugada das formas poéticas, uma dedicatória em que o gênio didático do homenageado aparece pela voz transcrita, que é testemunho e juízo, de um outro professor notável, num jogo interessante de reverberações, que só prova que uma aula, ainda que limitada no 
tempo (e no espaço), tem, quando é bem-sucedida, uma existência estranha, fantasmática, para além de si mesma; lê-se ali:

Ao Prof. Alfredo Bosi,

a mais perfeita vocação de professor da Universidade de S. Paulo (Antonio Candido), estas flores de uma erudição tardia, respingadas nas ruínas de um jardim abandonado,

oferece

Segismundo Spina

6 Como você situa Dante nos seus estudos da poesia moderna, no sentido mais amplo do termo? No seu livro Por que ler Dante (Globo, 2008), lemos que "as temporalidades mais diversas se encontram em choque, imbricam-se sem se conciliar, interpelam-se e questionam-se umas às outras" (p. 15-16), o que leva a um trabalho arqueológico atento não apenas à leitura da Comédia, mas de uma arqueologia da poesia moderna como você demonstrou em outros ensaios. De que modo esses estudos nos dão subsídios teóricos e críticos para a historiografia da literatura brasileira do século XXI?

Não sei se podemos estabelecer uma relação direta entre um momento e outro das minhas pesquisas, a não ser no sentido de que o que me interessou ao estudar Dante era compreender o modo como, através da literatura, ingressamos (primeira pessoa do plural sempre enganadora, porém, acredito, operacional) na modernidade - e hoje, na literatura contemporânea (que leio em conexão com um quadro históricocultural mais amplo que envolve antropologia, filosofia, fotografia, artes plásticas etc. - e que procurei desdobrar não só na forma de textos críticos e teóricos, mas também de exposições como Variações do corpo selvagem: Eduardo Viveiros de Castro, fotógrafo e Caixa-preta), me interessa entender o modo como vamos saindo da modernidade. Em suma, como disse, a relação a meu ver não é direta - porém, foi estudando Dante, sobretudo o seu momento inaugural anterior à Commedia, representado pela Vita Nova, seu primeiro livro (em que mistura poesia e prosa para recontar a formação da sua própria poesia como caso exemplar da formação do que depois conheceríamos como lírica moderna, a partir dos trovadores provençais), que pude observar em detalhe a emergência de algumas novidades que teriam uma longa sobrevida na literatura dos séculos seguintes: o uso do vernáculo, o predomínio de 
uma certa subjetividade que encena incessantemente seu apogeu e eclipse, a autoconsciência escritural que se faz prosa e como que exige a crítica e a teoria, a insuficiência da lírica como paradoxal motor da própria lírica etc. Esta é uma história que, com muitas oscilações e vaivéns, atravessa os sete séculos posteriores a Dante, chegando até nós - onde talvez esteja chegando a um dos seus fins. E esta é, claro, a "tradição" com que cada novo autor inevitavelmente tem de lidar — e não por acaso, na literatura brasileira contemporânea, são inúmeros os livros de poesia, mas também de prosa, em que é explícita a referência ao esquema tripartite da Commedia dantesca (Inferno, Purgatório, Paraíso). Mas isso é só um exemplo mais evidente - se formos aos pormenores, multiplicam-se e, por vezes, sutilizam-se os vínculos. Ademais, acredito que seja importante, para quem estuda literatura, saber se deslocar entre diferentes momentos históricos, de modo a ter ferramentas conceituais para perceber e descrever a espessura histórica constitutiva de cada texto literário, mesmo os mais contemporâneos.

\section{Qual a situação do ensino da literatura no Brasil? Quais seriam as} perspectivas pragmáticas para que as relações entre ensino e aprendizagem, práticas de leitura, debates possam se afirmar como uma utopia do presente diante de uma situação devastadora da política e sociedade brasileiras?

A pergunta é vasta e eu só me sinto autorizado a falar sobre o que diz respeito a esse estudo nas universidades - que é onde atuo. O que conheço do ensino de literatura nas escolas me chega muito por conta das alunas e alunos que trabalham como professores. Por um lado, pelos relatos deles, vejo que o interesse pela literatura, embora minoritário, permanece vivo, sobretudo quando o professor consegue desempenhar bem suas tarefas, seja por talento pessoal, seja por boas condições oferecidas pelas escolas. Por outro lado, há um aspecto que me preocupa muito: cada vez mais chegam-me relatos de censuras veladas ou explícitas a tópicos do ensino de literatura nas escolas, por parte dos gestores, que dizem agir em nome dos pais. Antes mesmo do governo Bolsonaro, que radicalizou a boçalidade no país, uma aluna ouviu de um administrador de sua escola que não poderia falar nada sobre o vínculo de Jorge Amado com o comunismo ao dar suas aulas, que, porém, não poderiam ignorar o autor de Capitães da areia. E há, como decorrência desse clima péssimo, a autocensura: professores que desistem de dar a aula que dariam, traindo 
seu próprio saber, para evitar possíveis sanções. Temo que isso, conforme o clima político piorar ao longo dos próximos anos (e tudo indica que vai piorar), possa chegar também às universidades. O que podemos e devemos fazer com relação a isso? Acho que cada vez mais é necessário fortalecer as redes de solidariedade entre as universidades e também - o que é quase inexistente - entre as universidades e as escolas.

\section{Ampliando o escopo da pergunta anterior, você teria uma hipótese sobre o} ensino de literatura no mundo contemporâneo? As variantes são diversas, indo desde novos dispositivos tecnológicos, humanidades em descrédito, precarização dos postos de professores e discursos de crise que sustentam e até administram esses aspectos.

A crise é constitutiva da literatura ao longo de toda sua trajetória histórica, que é, por isso mesmo, uma trajetória marcadamente moderna - é, como se sabe, a partir da modernidade e do conceito moderno de literatura, isto é, de um conceito desde o início em crise e sintomático de uma crise maior (da linguagem, da representação, do sujeito etc.), e que emerge como tal somente no século XVIII, que olhamos para o passado e falamos em literatura antiga ou literatura clássica, em literatura medieval, em literaturas orais etc. Assim sendo, tenho a impressão de que um ensino de literatura que levasse a sério a sua matéria e soubesse fazer também sua a crise constitutiva do seu objeto deveria estar mais preparado do que outras áreas de estudos para lidar com as inúmeras crises que atravessam e por vezes imobilizam a educação, as humanidades e a própria universidade no mundo contemporâneo. O pior que podemos fazer como professores, acho eu, é partir para uma simplificação e uma padronização cada vez maiores das perspectivas e dos métodos por meio dos quais examinamos, buscamos compreender e damos a ver a literatura. É preciso, ainda, resistir à submissão do ensino da literatura ao ensino da história e ao ensino da língua, por mais que não se possa pensar, para valer, a literatura sem levar em conta as dimensões da história e da língua. Esta é a prática escolar predominante, em que os textos literários aparecem como exemplos ancilares na transmissão de conteúdos alheios à própria literatura, como ilustrações. Ora, a literatura, quando funciona como literatura, isto é, como singularidade, não ilustra - ela, antes, perturba a transmissão de qualquer conhecimento, inclusive o conhecimento da própria literatura; ela inquieta 
os esquemas históricos e linguísticos (a história que ela conta põe em questão as historiografias consolidadas, mesmo as alternativas; a sua língua, que por vezes são línguas, no plural, não coincide com os padrões linguísticos hegemônicos, sejam cultos ou populares). É precisamente para isso - para as singularidades dos textos literários - que devemos continuar a chamar a atenção, acho eu. Se alguém conseguir fazer isso nos novos dispositivos tecnológicos, não se rendendo às exigências de facilitação que ferem no coração o que caracteriza a literatura como literatura, não vejo problema algum. Porém, com base na minha própria experiência com ensino emergencial à distância durante a pandemia, posso dizer, com algum grau de convicção, que o que chamamos de aula é e continua a ser um acontecimento presencial, que exige o encontro cara a cara de professor e alunos, para que se realize em todas as suas potencialidades, até porque só desta forma se estabelece o tipo de diálogo sem o qual não há uma boa aula. Mas isso, acho eu, não é exclusivo do ensino de literatura - embora neste, com a importância que tem a leitura dos textos (e sua releitura, ao menos em trechos, em meio às explicações e considerações), talvez a necessidade da copresença num mesmo ambiente físico seja ainda premente. Não por acaso, aliás, o significado primeiro de aula é pátio ou sala, em suma, assim nomeia-se um ambiente. A ideia de circunscrição física, já desde a etimologia, é importante, não acessória, na definição da aula.

\section{Como você atua em curadorias de exposição (ver Variações do corpo} selvagem, Eduardo Viveiros de Castro - Fotógrafo, com Veronica Stigger), como os espaços de museu, prioritariamente de apelo plástico e visual pode estabelecer mais interseções com textos literários e, de modo mais amplo, com ensaios e outras formas de saber em contato mais direto com a literatura?

Embora, na resposta anterior, eu tenha frisado a singularidade da literatura frente às outras formas de discurso e de saber, busco ser - na teoria e na prática um adepto aguerrido da transdisciplinaridade. Acredito que quem estuda apenas literatura não compreende sequer a literatura, ainda mais num tempo em que os próprios textos literários estão, de novo (é um fenômeno cíclico), abertos para outras linguagens e mesmo para outras disciplinas, assim como eles também se projetam, cada vez mais, para espaços não "literários" - há, por exemplo, exposições de literatura, assim como textos literários que chegam aos "leitores" como vídeos, 
performances, sites etc., e a tudo isso o professor, como o crítico, deve estar atento. Como curador eventual, busquei sempre produzir encontros interessantes entre as artes ditas visuais ou plásticas e a literatura - e quando digo "interessantes" estou pensando em encontros em que nem as obras visuais apareçam como ilustrações dos textos literários, nem o contrário, isto é, encontros em que cada obra e cada texto apareçam com suas potências próprias, sobretudo quando essas potências não se reduzem ao que se espera, convencionalmente, daquela arte determinada, que assim se indetermina. Também me interessa aquilo que, embora proveniente do campo literário, não é exatamente literatura - as atividades paralelas dos escritores, que sempre iluminam de modo inesperado aquilo que escreveram e complicam a compreensão dos seus textos. Só assim o experimento de montagem que chamamos de exposição resulta ele mesmo interessante. Vou dar um exemplo concreto. Fui um dos curadores, ao lado do Bernardo José de Souza, da Fernanda Brenner e da Veronica Stigger, de uma exposição chamada Caixa-preta, que ocorreu na Fundação Iberê Camargo, em Porto Alegre. No "prólogo" da exposição, no saguão do museu, colocamos, numa parede, uma série de exercícios de pintura do jovem lberê Camargo, cópias de obras alheias que ele fez em visitas a museus europeus, e, sobre uma mesa, coberta por uma redoma de acrílico, pusemos, de um lado, a Caixa-preta do Augusto de Campos com o Júlio Plaza e, do outro, o baralho de tarô do Caio Fernando Abreu; de um corredor ao fundo, que era na verdade o "epílogo" da exposição (que, porém, por conta da arquitetura da fundação, desembocava de novo no "prólogo", a modo de um ouroboros ou de um ricorso viquiano-joyciano), vinha o áudio das gravações que Hilda Hilst fazia de ruídos radiofônicos em busca de comunicação com os mortos. Ao longo da exposição, a literatura aparecia ainda na forma de um poema de Carlos Augusto Lima carimbado numa parede e da oralização gravada de um poema de Marília Garcia, tudo isso em meio a pinturas, esculturas, vídeos, instalações etc. Acho que a experiência da literatura e das demais artes que assim se arma pode nos ensinar algo sobre potencialidades ainda pouco percebidas dos textos.

10 Tempo da aula, tempo de crítica. Durante muito tempo, a temporalidade da crítica tinha uma esfera de circulação que ia do jornal (a crítica de folhetim, suplementos literários) para a sala de aula, passando ainda por editoras, de modo que a circulação tinha uma eficácia mais ampla. Na medida em que o 
espaço acadêmico se autonomizou, surgiu a impressão que existe um universo à parte que concilia o tempo da crítica literária, do ensino e dos debates. A questão não é nova, pois ela foi amplamente discutida ao longo dos anos noventa e dois mil, entre crítica universitária e crítica de folhetim, mas, na sua percepção, o que mudou?

O que mudou, a meu ver, foi que a crítica perdeu, quase totalmente, uma dimensão importantíssima, que é aquela constituída pelos jornais e revistas não exclusivamente literários ou culturais, por meio dos quais o crítico poderia, pelo menos em tese, alcançar um público por vezes não interessado especificamente em literatura. O que é sempre duvidoso, claro - é bem possível que apenas os interessados em literatura lessem as resenhas e ensaios publicados em jornais e revistas, e os demais leitores simplesmente saltassem do caderno de política para o de esportes, das notícias policiais para os classificados, sem sequer tomar conhecimento do que se pensava e dizia sobre os livros recém-publicados e sobre os autores e livros festejados em efemérides. No entanto, a ilusão de que o discurso sobre a literatura (e mais amplamente sobre as artes e a cultura) poderia chegar a um público mais amplo já produzia uma hipótese civilizacional bem mais saudável do que a certeza da vitória da barbárie em que vivemos agora. Respirava-se melhor, acho.

11 Quais são os pontos de contato e de atrito entre Portugal, África lusófona e Brasil, suas temporalidades complexas por histórias que ainda nos assombram, revoltam e fascinam e até que ponto a literatura, longe de toda e qualquer neutralidade, se imbrica com essas temporalidades?

Questão imensa. Respondo de forma sintética: por mais que as independências tenham produzido nações autônomas, o passado em comum que temos com Portugal e com a África (e, por meio da escravização de povos inteiros, inclusive com países africanos que não são de expressão portuguesa) continua a produzir efeitos sóciopolíticos no presente e também, não menos, efeitos literários. Se mais motivos não houvesse para nos sentirmos implicados nesta rede de relações e convocados ao conhecimento de autores e textos, este talvez já fosse suficiente. É a nossa história - ou melhor, são as nossas histórias que estão em questão. E justamente porque há um passado em comum, por mais desniveladas que sejam as experiências de cada 
lugar e de cada indivíduo no seu lugar (ou por isso mesmo: o desnivelamento produz singularidade e interesse), a reflexão brasileira sobre o racismo e a descolonização a partir da literatura pode se beneficiar da leitura, por exemplo, de um livro excepcional como o Caderno de memórias coloniais, da portuguesa nascida em Moçambique Isabela Figueiredo. Aliás, um livro sobre o qual escrevi quando sua edição brasileira foi publicada - e que me veio à mente recentemente, ao ler o romance mais recente de Paulo Scott, Marrom e amarelo, muito diferente do Caderno, mas imbuído do mesmo tipo de coragem da escrita.

12 Ainda pensando a aula como gênero em si, como uma aula pode ser simultaneamente um espaço de invenção, de crítica e reelaboração de tudo aquilo que se situa nas margens historiográficas, seja pela cegueira do presente ou pelos modos de situar novamente o que estava às margens ou reforçado pela própria historiografia literária?

Uma aula é um espaço experimental por excelência, justamente porque nela não há a ilusão de permanência que costuma acometer os textos escritos - ilusão que, muitas vezes, bloqueia as hipóteses mais arriscadas, que teriam a capacidade de fazer avançar o conhecimento e o pensamento de uma área de estudos. Por isso mesmo que gosto muito de levar para as aulas que dou as hipóteses com que estou trabalhando em textos, de modo a testá-las, não no sentido de ver se convencem, mas, sim, no sentido de verificar se elas estimulam o diálogo, se elas são produtivas, daquela forma que podem ser produtivas as asserções teóricas e críticas, isto é, pela capacidade que elas têm de suscitar diálogos e questionamentos - e outras hipóteses. Esta é, aliás, uma boa maneira de avaliar uma hipótese de leitura observar se ela foi capaz de gerar outras hipóteses. Fico feliz quando percebo que algo que falei em aula, e que às vezes ainda não tomou forma de um texto, acabou resultando no trabalho de algum aluno, às vezes até em teses de doutorado. $\mathrm{E}$, quando falo em hipóteses de leitura, talvez seja o caso de frisar leitura: porque, a meu ver, uma aula passa muito por aí, no seu centro deve estar, a meu ver, sempre um ato de leitura, ou antes, quando o professor tem sorte de contar com alunos afinados e dispostos, um ato de múltiplas leituras em diálogo, em convergência e divergência. Por isso gosto de projetar textos no quadro - poemas ou trechos de prosa - e comentá-los ponto por ponto com os alunos. As aulas muito abstratas ou 
esquemáticas me incomodam, pois arriscam perder de vista a concretude dos textos, que não são objetos ideais, mas coisas com sua materialidade própria, com seus lapsos e suas fulgurações, que cabe ao professor destacar. Lembro de um fato engraçado: uma colega, que é também uma amiga, recomendou a um aluno dela que acompanhasse um curso meu; comecei o curso lendo detidamente, ao longo de três ou quatro aulas, parágrafo por parágrafo, chamando a atenção para as recorrências de palavras e figuras e para as próprias articulações das frases, a primeira parte de Os sertões, de Euclides da Cunha ( $A$ terra). Minha colega me contou que um dia encontrou aquele aluno e perguntou como estavam indo as aulas - e o aluno lhe disse que iam bem, mas que as minhas não eram exatamente aulas de literatura. Por aí acho que se vê como se naturalizou, na esfera dos estudos literários, a ênfase na esquematização abstratizante contra a concretude dos textos - já eu prefiro voltar sempre aos textos, acho que eles sempre guardam surpresas que um professor pode tentar revelar aos alunos, inclusive para desmantelar os esquemas, que, embora tantas vezes úteis, podem ser um limite para o pensamento e uma traição ao conhecimento.

\section{Para concluir, você escreveu um pequeno e preciso ensaio sobre a alegria} (Lumme editor, 2008), lendo-a como tarefa a partir de alguma poesia moderna. Quais seriam os impasses da alegria na situação atual, como tarefa e como perspectiva política da leitura e do ensino da literatura?

Se bem recordo o que escrevi naquele ensaio de 2008, chamo a atenção, lá, para o fundo trágico da reivindicação da alegria, para o fato de que a alegria é um afeto político por excelência, porque é uma afirmação da potência de vida contra o poder de morte - e que, portanto, não podemos simplesmente esquecer o domínio da morte, mas combatê-lo com as armas à nossa disposição. "A felicidade do homem é uma felicidade guerreira", escreveu Oswald de Andrade, autor fundamental no meu ensaio. Por isso mesmo falo em alegria como tarefa, como munus - e, portanto, como princípio de qualquer comunidade válida (porque há também os vínculos comunitários fundados na repressão, e até mesmo no terror, e estes devem ser combatidos: são inválidos, não valem, ou ao menos não deveriam valer, muito menos deveriam ser o padrão, como parecem ser por ora). O ensino faz sentido quando ele tem como meta a constituição dessa comunidade da alegria. Uma aula, quando funciona, talvez seja 
um vislumbre dessa "comunidade que vem", para recordar a expressão de Agamben. Diante de um quadro político e social de recrudescimento do fascismo, não só no Brasil mas também nas outras partes do mundo, acho que fica evidente a função decisiva - diria até vital - que pode ter uma aula assim concebida.

\section{Referências}

CANDIDO, A. Direito à literatura. In: CANDIDO, A. Vários Escritos. Rio de Janeiro, Ouro sobre Azul, 2011.

CORDEIRO, D. S.; FURTADO, J. P. Arte da Aula. São Paulo, Sesc, 2019. 